\title{
Erratum to: Electrical properties of a new sulfur-containing polymer for optoelectronic application
}

EIMehdi EIAkermi $^{1} \cdot$ Nejmeddine Jaballah $^{1} \cdot$ Hafedh Ben Ouada $^{1}$. Mustapha Majdoub $^{1}$

Published online: 29 May 2015

(c) Springer-Verlag Berlin Heidelberg 2015

Erratum to: Appl. Phys. A (2015) 119:1335-1342

DOI 10.1007/s00339-015-9100-9

The original version of this article unfortunately contained a mistake.

The spelling of the corresponding author was incorrect. The correct name is ElMehdi ElAkermi.

The online version of the original article can be found under doi:10.1007/s00339-015-9100-9.

ElMehdi ElAkermi

mehdi.fsm@gmail.com

1 Laboratory of Interfaces and Advanced Materials, Faculty of

Sciences of Monastir, University of Monastir, Bd de

l'Environnement, 5019 Monastir, Tunisia 